\title{
FORMULASI DAN PENINGKATAN MUTU MASKER WAJAH DARI BIJI KAKAO NON FERMENTASI DENGAN PENAMBAHAN RUMPUT LAUT
}

\author{
Formulation and quality improvement of non fermented cocoa bean face masks \\ with seaweed addition
}

\author{
Wahyuni, Alfrda Lullung, Dyah Wuri Asriati \\ Balai Besar Industri Hasil Perkebunan \\ JI.Prof .Dr. Abdurrahman Basalamah No.28 Makassar 90231 \\ Pos-el: wahyunibjbr@yahoo.co.id
}

(Artikel diterima 15 November 2016; direvisi 5 Desem,ber 2016; disetujui 12 Desember 2016)

\begin{abstract}
A research on formulation and quality improvement of non fermented cocoa bean face masks with seaweed addition has been done. The purpase of this study was to improve the quality of non fermented of cocoa bean face mask with seaweed addition to obtaine the most optimal stability. By keeping all other ingredients composition constant, the seaweed addition was varied $(15,20,25)$ grams, and propylene glycol $(10,7.5,5)$ grams refers to a preliminary study of 2.5 grams cocoa paste used for 250 grams creams receipe. The results showed that non fermented cocoa beans can be processed as raw materials for the skin care health products (face mask cream). Face mask cream stability test of all formulas with concentrations of $15 \mathrm{~g}$ of seaweed, 10 propylene glycol showed a better quality complied with cosmetics qualification as face mask cream compared with other compositions on centrifuges test, homogeneity, freeze thaw, physical stability, $\mathrm{pH}(7.77)$ and test viscosity $(1.35) \times 10^{3} \mathrm{cp}$. In vitro toxicity test of seaweed face mask cream did not cause irritation effects on the skin.
\end{abstract}

Keywords: Face mask cream, cocoa paste, seaweed, stability, skin irritation

\begin{abstract}
Abstrak. Penelitian formulasi dan peningkatan mutu masker wajah dari biji kakao non fermentasi dengan penambahan rumput laut telah dilakukan. Penelitian ini bertujuan untuk meningkatan mutu formulasi krim masker wajah dari biji kakao dengan penambahan rumput laut yang mempunyai kestabilan yang paling optimal. Variasi jumlah Rumput Laut yang ditambahkan, yaitu 15, 20 dan $25 \mathrm{~g}$ dan propilen glikol yaitu 10, $7,5,5 \mathrm{~g}$ mengacu pada penelitian pendahuluan dengan penggunaan pasta kakao yang konstan, yaitu $2,5 \mathrm{gr}$ untuk $250 \mathrm{gr}$ resep krim dan sedangkan komposis bahan tambahan formula lainnya dibuat tetap. Hasil penelitian menunjukkan bahwa biji cokelat non fermentasi dapat diolah sebagai bahan baku produk untuk kesehatan perawatan wajah ( krim masker wajah). Uji stabilitas Krim masker wajah dari semua formula dengan konsentrasi pasta cokelat dan rumput laut untuk uji sentrifuga, uji viskositas, freeze thaw, $\mathrm{pH}$ dan uji homogenitas formula $15 \mathrm{~g}$ rumput laut, 10 propilen glikol memiliki kualitas yang lebih baik yang memenuhi syarat kosmetik sebagai krim masker wajah dibanding dengan komposisi lainnya dalam hal homogenitas, kestabilan fisik, $\mathrm{pH}(7,77)$ dan viskositas $(1,35) \times 10^{3} \mathrm{cp}$. Uji toksisitas secara in-vitro terhadap krim masker rumput laut tersebut tidak menyebabkan iritasi pada kulit.
\end{abstract}

Kata Kunci : Krim masker wajah, pasta kakao, rumput laut, stabilitas, iritasi kulit

\section{PENDAHULUAN}

Kakao merupakan komoditi yang mempunyai nilai ekonomis yang tinggi, karena mempunyai manfaat yang sangat luas terutama dalam industri makanan, minuman, farmasi, kosmetik, industri Cacao fermented beam. Biji coklat fermentasi selama ini banyak diekspor keluar negeri sebagai bahan makanan/minuman, sementara biji coklat non fermentasi hanya digunakan sebagian besar hanya sebagai bahan tambahan makanan/ minuman yang berbasis coklat dan sebagian lagi digunakan sebagai bahan pewarna, biji coklat fermentasi kebanyakan diekspor ke negara Eropa dan biji coklat non fermentasi banyak di ekspor ke Amerika Serikat dan negara tetangga seperti ke Singapura. Dibanding biji coklat sebagai komoditi ekspor terbesar, ekspor kakao dalam bentuk olahan sangatlah sedikit jumlahnya hanya sekitar 17 - $20 \%$ (Rosniati , dkk , 2005). Dalam rangka diversifikasi pemanfaatan biji coklat non fermentasi akan diarahkan bukan saja 
sebagai bahan makanan/minuman tetapi lebih diarahkan kepada produk kesehatan baik sebagai makanan kesehatan (fungsional food) maupun sebagai produk kesehatan dalam rangka perawatan kulit baik sebagai masker/lulur, dan lain-lain.

Buah kakao secara garis besar terdiri tiga bagian, yaitu kulit buah $75,67 \%$, plasenta 2,59\%, dan biji kakao 21,74\%. Buah kakao yang masak memiliki kulit tebal dan berisi 30 -40 biji yang diselimuti oleh plasenta.

Biji kakao non fermentasi sebagai makanan kesehatan maupun sebagai produk perawatan kulit karena kaya akan nutrisi sebagai anti oksidan yang dapat menolak racun dalam tubuh baik untuk pemakaian dalam maupun untuk pemakaian luar.

Kornponen-komponen

khusus

menurut Bernard, W. Minifie (1980) antara lain adalah : polifenol/flavonoid (antocyanin, leucoantocyanin $3 \%$, catechol/catechin $3 \%$ dan polifenol kompleks) yang berguna sebagai anti oksidan baik sebagai makanan kesehatan maupun sebagai perawatan kulit.

Sebagai perawatan kulit karena adanya lemak sebagai emollient yang mengandung vitamin $\mathrm{E}$ dan berfungsi sebagai anti oksidan yang dapat mencegah masuknya radikal bebas yang dapat mengganggu aktifitas enzim selain itu vitamin $E$ dapat mencegah pengerutan dan penuaan pada kulit.

Rumput laut adalah tanaman yang liar dan tumbuh dilautan yang merupakan kategori algae atau ganggang. Rumput laut memiliki ciri dan bentuk yang beragam, salah satunya memiliki bentuk yang pipih dan bercabang. Dalam kandungan rumput laut itu sendiri mengandung nutrisi alami seperti vitamin $A, B 1, B 2, B 12, C, D, E, F, K$, mineral dan asam lemak yang baik bagi tubuh.

Manfaat Rumput laut untuk kecantikan karena mengandung mineral yang sangat kaya dan dibutuhkan oleh kulit seperti Vitamin B kompleks, vitamin C, Magnesium, dan berbagai mineral lainnya yang membantu metabolisme sel kulit. Kandungan mineral yang ada pada rumput laut dapat melancarkan metabolisme aliran darah dan mengeluarkan racun yang ada pada tubuh.
Rumput laut mengandung Antioksidan. Senyawa fenol yang terdapat pada rumput laut adalah senyawa yang berfungsi sebagai antioksidan, selain itu rumput laut kaya juga serat lodium dan mineral - mineral penting lainnya. Radikal bebas adalah suatu molekul sifatnya sangat stabil dan sangat reaktif sehingga dapat menimbulkan kerusakan pada tubuh manusia, disinilah sebenarnya fungsi dari Antioksidan disamping manfaat lainnya seperti mencegah pemicu penyakit regeneratif. Pemakaian rumput laut dalam bentuk masker secara teratur bisa membuat kulit halus dan bercahaya. Kulit pun akan terlihat segar dan berseri, selain itu akan terlihat awet muda dan terhindar dari masalah jerawat. Tidak hanya itu rumput laut yang berwarna coklet juga dipercaya dapat mengatasi jerawat yang terjadi pada kulit wajah, rumput laut cokelat mempunyai efek anti-inflamasi (anti radang) untuk membantu mengurangi pembengkakan jerawat.

Kegiatan penelitian formulasi dan peningkatan mutu masker wajah dari biji kakao non fermentasi dengan penambahan rumput laut ini dimaksudkan untuk memanfaatkan biji coklat non fermentasi dan rumput laut sebagai bahan baku produk untuk kesehatan dan perawatan kulit wajah (masker). Penelitian ini bertujuan untuk meningkatkan mutu formulasi krim masker wajah dari biji kakao dengan menambahkan rumput laut yang mempunyai kestabilan yang paling optimal.

\section{METODOLOGI}

\section{Bahan dan alat}

Bahan yang digunakan pada penelitian ini meliputi biji kakao non fermentasi dan rumput laut jenis ecottoni yang bersal dari daerah Bantaeng. Adapun bahan penolong yang digunakan Zink Oksida, Veegum, Propilen Glikol, Asam Stearat, Emulgator (novemer), Metil Paraben, Propil Paraben, Alkohol 70\%, Setil Alkohol,Aquabidest.

Alat yang digunakan mencakup Spectrofotometer, AAS, Centrifuga Hettich, Brookfield Helipeth Stand, tanur, oven, waterbath, mixer dan alat alat gelas lainnya untuk analisis. 
Metode Penelitian

Metode penelitian mencakup formulasi dan analisis sediaan masker wajah rumput laut bentuk krim yang diformulasi dari pasta kakao non fermentasi dan rumput laut jenis e-cottoni.

Penelitian mencakup penelitian pendahuluan yang menggunakan formula dari penelitian yang telah dilakukan yaitu masker wajah dari pasta kakao dan dilanjutkan dengan penelitian lanjutan.

Penelitian pendahuluan bertujuan menentukan perbandingan pasta kakao dengan kolagen rumput laut dalam satu resep produk, yang secara visual menghasilkan Masker bentuk krim yang tidak menunjukkan terjadinya pemisahan fase cair dengan fase minyak. Pada tahap ini dilakukan pada 2 komposisi bahan yang dapat dilihat pada Tabel.1.

\section{Tabel 1. Komposisi Bahan Masker Wajah pada Penelitian Pendahuluan}

\begin{tabular}{lcc}
\hline \multirow{2}{*}{\multicolumn{1}{c}{ Bahan }} & \multicolumn{2}{c}{ Formula (\%) } \\
\cline { 2 - 3 } & F1 & F2 \\
\hline Pasta (A) & 5 & 2,5 \\
Rumput Laut & 15 & 20 \\
Zink Oksida & 5 & 2,5 \\
Veegum & 5 & 5 \\
Propilen Glikol & 10 & 7,5 \\
Asam Stearat & 1 & 0,5 \\
Emulgator & 1 & 1,25 \\
Metil Paraben & 0,9 & 0,9 \\
Propil Paraben & 0,02 & 0,02 \\
Alkohol 70\% & 20 & 20 \\
Setil Alkohol & 0,5 & 0,5 \\
Aquabidest & 45,58 & 45,58 \\
\hline
\end{tabular}

Pada penelitian lanjutan, jumlah pasta divariasikan kembali dengan mengacu pada hasil penelitian yang telah dilakukan dua varian. Mutu krim masker wajah rumput laut diujikan pada laboratorium, yang meliputi uji Mikrobiologi yaitu penentuan angka lempeng total menggunakan bakteri aerob, penentuan angka kamir kapang dan uji efektifitas pengawet.

Uji tambahan iritasi kulit dilakukan terhadap krim masker rumput laut dengan stabilitas terbaik dari ketiga formula berdasarkan parameter uji tersebut. Pengujian dilakukan secara invitro dengan menggunakan kelinci albino, galur New Zaeland (hybrid) dengan bobot $>2 \mathrm{~kg}$ (sesuai panduan WHO). Kelinci diaklimatisasi terlebih dahulu selama 3 hari di Laboratorium Pemeliharaan Kelinci sebelum digunakan (Ritten dan Franklin).

Pada uji kestabilan homogenitas sediaan krim masker wajah rumput laut dioleskan tipis tipis pada permukaan kaca objek kemudian diamati homogenitasnya dibawah mikroskop. Untuk mendapatkan permukaan yang homogen dilakukan dengan menggeser sejumlah sediaan dari ujung satu sampai ujung lainnya dengan menggunakan bantuan kaca objek yang lain.

Pada uji kestabilan fisik dengan metode sentrifugasi, sediaan krim masker ditimbang sebanyak $2 \mathrm{gr}$ dan dimasukkan kedalam tabung sentrifugasi lalu disentrifus pada kecepatan 3750 rpm selama 5 jam. Pengamatan dilakukan terhadap terjadinya pemisahan fase minyak dan fase cair pada setiap interval waktu 1 jam. Uji dilakukan untuk setiap formulasi krim masker wajah rumput laut.

Untuk uji iritasi kulit, digunakan 3 ekor kelinci dengan bobot masing - masing $>2$ $\mathrm{kg}$ dan telah diaklimatisasi terlebih dahulu selama 3 hari. Satu hari sebelum percobaan punggung kelinci dibersihkan dari bulu dengan mencukur bulu tersebut. Pada punggung kelinci yang sudah dibersihkan disiapkan dua daerah uji masing - masing pada sisi kanan dan sis kiri. Pada masing masing daerah tersebut dioleskan sediaan krim masker rumput laut sebanyak 500 mg, kemudiaan ditutup dengan kaca hipoalergik kertas selafon dan diperban dengan perban elastis. Pengamatan dilakukan setelah 0 (sebelum dioleskan sediaan), 24, 48, dan 72 jam dengan parameter eriterna, eskar dan udem serta efek - efek lain yang timbul (Hayes,2001). Bila setelah 24 jam pertama tidak terjadi iritasi pada kulit, maka pengamatan dilanjutkan setelah 48 jam, dan seterusnya. 
Proses pembuatan masker wajah rumput laut

Menyiapkan kolagen rumput laut dengan cara timbang 100 gr rumput laut bersihkan dengan cara mencucinya hingga bersih 5-6 kali,lakukan perendaman selama 8 jam dan ganti air rendaman setiap 2 jam, angkat dan tiriskan hingga air rendaman tuntas, blender agar benar - benar halus, rebus 15 -20 menit kedalam 2,5 liter air, simpan dalam lemari es.

Masing-masing bahan ditimbang dengan kebutuhan, pasta kakao disatukan dengan zink oksida ( $\mathrm{ZnO})$, veguum hingga homogen. Bahan - bahan senyawa fase minyak yaitu asam stearat, setil alkohol dilebur diatas penangas air. Setelah melebur sempurna, dilarutkan propil paraben sambil diaduk hingga suhunya mencapai $70^{\circ} \mathrm{C}$. Bahan senyawa fase cair yaitu metil paraben dibuat dengan cara melarutkan bahan tersebut kedalam air yang telah dipanaskan hingga suhu $70^{\circ} \mathrm{C}$, kemudian ditambahkan propilen glikol sambil suhu tetap dipertahankan pada suhu $70^{\circ} \mathrm{C}$.

Masker wajah rumput laut dibuat denga cara bahan fase minyak ditambahkan sedikit demi sedikit. Secara terus menerus kedalam bahan - bahan fase cair sambil diaduk dengan mixer selama dua menit. Hasil pencampuran kemudian didiamkan selama 30 detik, dilanjutkan dengan pengadukan sampai terbentuk cairan kental. Campuran pasta kakao, zink oksida dan veegum kemudian ditambahkan kedalam campuran fase minyak dan fase cair secara perlahan sedikit demi sedikit. Jika suhu sudah mencapai $50^{\circ} \mathrm{C}$ ditambahkan emulgator novemmer dan dilakukan pengadukan dengan kecepatan tingggi hingga terbentuk basis krim kemudian tambahkan kolagen rumput laut dan alkohol sambil terus diaduk sampai homogen. Pengadukan dihentikan jika krim masker wajah rumput laut yang terbentuk mempunyai tekstur yang halus. Selanjutnya dikemas dalam tube yang telah disterilkan.

\section{HASIL DAN PEMBAHASAN}

\section{Penelitian Pendahuluan}

Dari hasil penelitian, teramati secara visual bahwa penggunaan pasta kakao $2,5 \mathrm{~g}$, emulgator 1,25 dan rumput laut $15 \mathrm{~g}$ menghasilkan masker berbentuk krim (semi padat) dengan tekstur lembut dan tercampur sempurna (tidak terjadi pemisahan fase cair dan fase minyak). Pengamatan dilakukan setelah dua minggu penyimpanan produk masker. Penggunaan $5 \mathrm{~g}$ pasta kakao dengan emulgator $1,25 \mathrm{~g}$ dan rumput laut $20 \mathrm{~g}$, menghasilkan krim yang cenderung berbentuk gumpalan-gumpalan, dimana terjadi pemisahan antara fase cair dan fase minyak. Hal ini menunjukkan tidak terjadi keseimbangan antara ukuran dan kekuatan gugus hidrofilik (non polar) dari emulgator. Semakin polar suatu molekul maka emulgator akan semakin mudah masuk ke fase cair dari emulsi tersebut. Sebaiknya semakin non polar bagian yang lain, maka emulgator akan semakin menjadi bagian dari fase minyak.

Berdasarkan hasil penelitian tersebut disusunlah formula krim masker wajah rumput laut dengan komposisi pasta kakao masing - masing $2,5 \mathrm{~g}$ dengan variasi rumput laut 15,20 dan $25 \mathrm{~g}$, propilen glikol sebagai bahan tambahan dengan variasi $10,7,5$ dan $5 \mathrm{~g}$, dan dimana komposisi bahan lainnya konstan. Rancangan formula tersebut dapat dilihat pada tabel 2 .

Tabel. 2. Komposisi Bahan Sediaan Masker Wajah Rumput laut.

\begin{tabular}{lccc}
\hline \multirow{2}{*}{\multicolumn{1}{c}{ Bahan }} & \multicolumn{3}{c}{ Formula \% } \\
\cline { 2 - 4 } & I & II & III \\
\hline Pasta (A) & 2,5 & 2,5 & 2,5 \\
Zink Oksida & 2,5 & 2,5 & 2,5 \\
Veegum & 5 & 5 & 5 \\
Propilen Glikol & 10 & 7,5 & 5 \\
Asam Stearat & 0,5 & 0,5 & 0,5 \\
Emulgator (B) & 1,25 & 1,25 & 1,25 \\
Metil Paraben & 0,9 & 0,9 & 0,9 \\
Propil Paraben & 0,02 & 0,02 & 0,02 \\
Alkohol 70\% & 20 & 20 & 20 \\
Setil Alkohol & 0,5 & 0,5 & 0,5 \\
Aquadest & 45,58 & 45,58 & 45,58 \\
Rumput Laut & 15 & 20 & 25 \\
\hline
\end{tabular}




\section{Uji Homogenitas dan Stabilitas}

Uji Homogenitas krim masker wajah rumput laut untuk ketiga formula disajikan pada Tabel 4 , sedangkan hasil uji stabilitasnya disajikan pada tabel 3 .

Tabel 3. Hasil Uji Sentrifugasi Bahan Sediaan Masker Wajah Bentuk Krim

\begin{tabular}{|c|c|c|c|c|c|}
\hline \multirow{2}{*}{ Formula } & \multicolumn{5}{|c|}{ Waktu sentrifugasi (jam) } \\
\hline & 1 & 2 & 3 & 4 & 5 \\
\hline $\mathrm{I}$ & $\begin{array}{l}\text { Tidak } \\
\text { stabil }\end{array}$ & $\begin{array}{l}\text { Tidak } \\
\text { stabil }\end{array}$ & $\begin{array}{l}\text { Tidak } \\
\text { stabil }\end{array}$ & $\begin{array}{l}\text { Tidak } \\
\text { stabil }\end{array}$ & $\begin{array}{l}\text { Tidak } \\
\text { stabil }\end{array}$ \\
\hline II & $\begin{array}{l}\text { Tidak } \\
\text { stabil }\end{array}$ & $\begin{array}{l}\text { Tidak } \\
\text { Stabil }\end{array}$ & $\begin{array}{l}\text { Tidak } \\
\text { stabil }\end{array}$ & $\begin{array}{l}\text { Tidak } \\
\text { stabil }\end{array}$ & $\begin{array}{l}\text { Tidak } \\
\text { stabil }\end{array}$ \\
\hline III & $\begin{array}{l}\text { Tidak } \\
\text { stabil }\end{array}$ & $\begin{array}{l}\text { Tidak } \\
\text { stabil }\end{array}$ & $\begin{array}{l}\text { Tidak } \\
\text { stabil }\end{array}$ & $\begin{array}{l}\text { Tidak } \\
\text { stabil }\end{array}$ & $\begin{array}{l}\text { Tidak } \\
\text { stabil }\end{array}$ \\
\hline
\end{tabular}

Meski pada uji homogenitas ketiga formulasipastakakao menunjukkan homogen (Tabel.4), tetapi pada uji sentrifugasi formula I, II dan III tidak stabil bahkan cenderung pecah hingga 5 jam sentrifusi pada kecepatan 3750 rpm. Hal ini kemungkinan disebabkan oleh tidak tercampurnya dengan sempurna dan tidak seimbangnya jumlah pasta kakao, kolagen rumput laut dan emulgator sebagai pengemulsi didalam formula. Sebagaimana diketahui asam stearat didalam lemak kakao merupakan asam lemak jenuh yang bersifat memadatkan, disamping sebagai senyawa fase minyak. Jumlah yang berlebihan dapat menyebabkan produk pecah. Karena itu, penggunaan asam stearat perlu diperhatikan jumlahnya sampai batas - batas tertentu (Duma, 2013). Juntawong et.al. (2010) pada eksperimen pembuatan krim pelembab kulit menyatakan bahwa sampai batas tertentu penambahan bahan minyak atau lemak pada konsentrasi emulsifier tertentu menyebabkan emulsi pecah atau terpisah kedalam fase cair dan fase minyak, sehingga hasil krim menjadi pecah.

\section{Uji pH}

Hasil uji pH krim masker wajah rumput laut untuk ketiga formula disajikan pada Tabel 4 .
Tabel 4. Hasil Uji Sediaan Masker Wajah Bentuk Krim Rumput Laut.

\begin{tabular}{|c|c|c|c|}
\hline Formula & I & II & III \\
\hline Homogenitas & \multicolumn{3}{|c|}{ Homogen Homogen Homogen } \\
\hline $\mathrm{pH}$ & 7, & 7,82 & 7,65 \\
\hline $\begin{array}{l}\text { Viskositas } \\
\left(10^{3} \mathrm{cp}\right)\end{array}$ & 1,35 & 2,22 & 4,45 \\
\hline
\end{tabular}

Hasil uji pH berada pada kisaran 7,65 sampai 7,82, dimana nilai pH formula I sebesar 7,77 . Menurut produk kosmetik sebaiknya dibuat sesuai dengan $\mathrm{pH}$ kulit sesuai standar SNI 16-4399-1996 untuk pelembab kulit yang mensyaratkan $\mathrm{pH}=4,5-8,0$ (BSN, 1996), nilai $\mathrm{pH}$ sediaan krim masker masih berada pada persyaratan tersebut, meski mendekati ambang batasnya.

\section{Uji Viskositasnya}

Uji viskositas terhadap ketiga formula krim masker wajah rumput laut mempunyai hubungan dengan kestabilan. Untuk ketiga formula Uji viskositas dilakukan dengan menggunakan alat Brookfied dan alat spindel TD dan TE kecepatan 5 rpm dengan waktu pengamatan 5 (lima) menit. Hasil uji viskositas krim masker wajah untuk ketiga formula disajikan pada Tabel 4.

Rentang viskositas sampel antara $(1,35) \times 10^{3} \mathrm{cp}-(4,45 \pm 0,006) \times 10^{3} \mathrm{cp}$. Sampel W1 mempunyai viskositas $(1,35) \times 10^{3} \mathrm{cps}$ merupakan krim yang paling stabil secara fisik dengan nilai viskositas paling kecil.

Viskositas krim merupakan kriteria penampilan pokok, penggunaannya tidak berkenaan dengan nilai viskositas absolut, tetapi melihat pada perubahan viskositas pada selama penyimpanan. Semakin kecil perubahan viskositas maka semakin stabil krim tersebut. Pengamatan viskositas krim menunjukkan terjadi kenaikan viskositas pada semua variasi konsentrasi. Hal ini merupakan efek normal penyimpanan suatu emulsi pada suhu yang lebih tinggi adalah mempercepat koalesensi dan hal ini biasanya diikuti dengan perubahan viskositas. Selain itu, perbedaan temperatur secara bergantian menyebbkan terjadinya penguapan air dari sediaan sehingga viskositas krim meningkat. Kebanyakan emulsi menjadi lebih encer 
pada suhu tinggi dan menjadi lebih kental bila dibiarkan mencapai suhu dingin.

\section{Uji Iritasi Kulit}

Hasil uji iritasi kulit dari formula 1 dengan penggunaan 2,5 gr pasta kakao dan $15 \mathrm{~g}$ kolagen rumput laut disajikan pada Tabel 5.

Kesimpulan: sediaan masker tidak bersifat mengiritasi kulit.
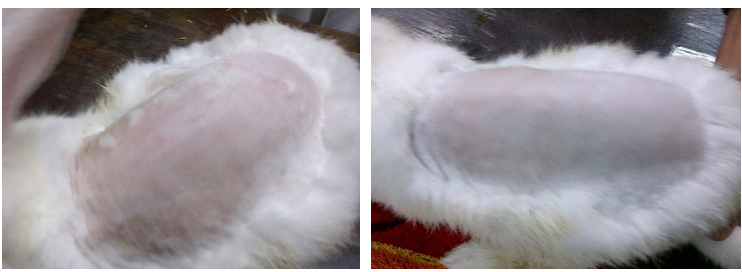

Gambar 1. Foto kelinci normal dengan kulit sebelum dioles sampel
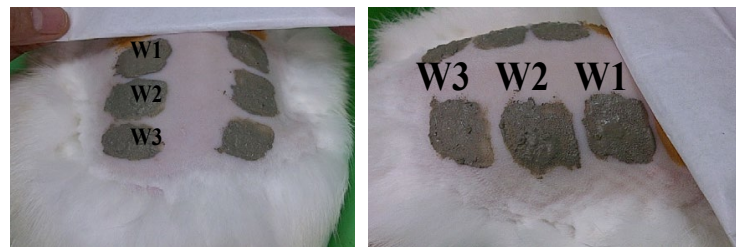

Gambar 2. Foto kulit kelinci yang dioles sampel uji
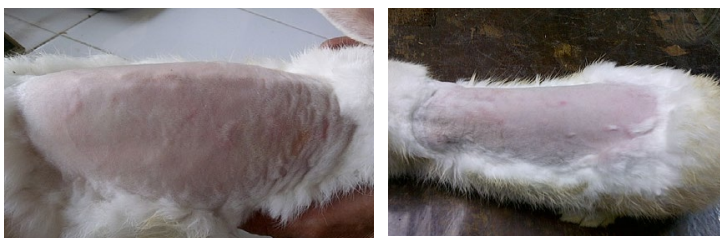

Gambar 3. Hasil Uji Iritasi Pada Kulit Kelinci Pangamatan

Tabel. 5. Hasil Uji Iritasi Kulit Sediaan Masker Wajah Bentuk Krim

\begin{tabular}{|c|c|c|c|c|c|c|c|c|c|c|c|c|c|}
\hline \multirow{3}{*}{$\begin{array}{l}\text { Periode } \\
\text { pengujian } \\
\text { (Jam) }\end{array}$} & \multicolumn{4}{|c|}{ Kellinci } & \multicolumn{4}{|c|}{ Kellinci } & \multicolumn{4}{|c|}{ Kellinci } & \multirow[t]{3}{*}{ IIKP } \\
\hline & \multicolumn{2}{|c|}{ Kiri } & \multicolumn{2}{|c|}{ Kanan } & \multicolumn{2}{|c|}{ Kiri } & \multicolumn{2}{|c|}{ Kiri } & \multicolumn{2}{|c|}{ Kanan } & \multicolumn{2}{|c|}{ Kiri } & \\
\hline & $E$ & U & $E$ & $\mathrm{U}$ & $E$ & $U$ & $E$ & $U$ & $E$ & $U$ & $E$ & $U$ & \\
\hline 0 & 0 & 0 & 0 & 0 & 0 & 0 & 0 & 0 & 0 & 0 & 0 & 0 & \\
\hline 24 & 0 & 0 & 0 & 0 & 0 & 0 & 0 & 0 & 0 & 0 & 0 & 0 & 0 \\
\hline 48 & 0 & 0 & 0 & 0 & 0 & 0 & 0 & 0 & 0 & 0 & 0 & 0 & \\
\hline 72 & 0 & 0 & 0 & 0 & 0 & 0 & 0 & 0 & 0 & 0 & 0 & 0 & \\
\hline$d$ & & & & & & & & & & & & & \\
\hline
\end{tabular}

$$
E=\text { eritema; } \quad U=\text { udem }
$$

Pada Tabel 5 terlihat bahwa formula 1 krim masker wajah rumput laut tidak menyebabkan iritasi kulit pada kelinci percobaan sampai ke 27 pengamatan. Hal ini disebabkan karena konsentrasi masing - masing senyawa yang digunakan pada formula masih dibawah nilai ambang batas atau masih diperbolehkan. Misalnya setil alkohol merupakan senyawa yang aman digunakan pada produk makanan dan kosmetik karena telah dievaluasi dan diuji oleh Cosmetic Ingredient Review (IR) Expert Panel. Fatmawati et al., 2012 mengatakan bahwa propilen glikol merupakan cairan kental yang jernih, tidak berwarna, praktis tidak berbau dengan sedikit rasa manis menyerupai gliserin. Propilen glikol digunakan sebagai humektan dalam sediaan kosmetik dengan konsentrasi hingga $15 \%$. Duma (2014) juga melaporkan tidak terjadi iritasi kulit pada lasion yang diformulasi dari lemak kakao. Penggunaan pengawet propil paraben dan metil paraben masing - masing 0,05 dan $0,45 \mathrm{~g}$ produk losion.

\section{SIMPULAN}

Dari hasil dan pembahasan dapat disimpulkan bahwa peningkatan mutu formula masker wajah rumput laut dengan 
penggunaan pasta kakao 2,5 g dan $10 \mathrm{~g}$ rumput laut dapat menghasilkan sediaan krim masker yang homogen, stabil, nilai $\mathrm{pH}$ yang masih memenuhi syarat dan viskositas yang cukup baik.

Uji iritasi menunjukkan krim yang tidak beriritasi pada kulit. Perhatian harus diberikan karena nilai pH sudah mendekati nilai ambang batas atas syarat sebagai pelembab kulit.

\section{DAFTAR PUSTAKA}

Andi Syamsul Bakhri, 2011, Pengaruh Emulgator Novemmer Dan Viscolam Terhadap Kestabilan Fisik Krim Dari Kombinasi Ekstrak Etanol Akar Murbei (Morus alba L.) Dan Buah Mahkota Dewa (Phaleria macrocarpa Boerl.), Fakultas Farmasi Universitas Hasanuddin Makassar

BSN, Kakao Massa, SNI 3749 - 2009

Buckle et al., 1987. Ilmu Pangan,(Penerjemah Hari Purnomo dan Adiono), Penerbit; Universitas Indonesia (UI Press), Jakarta.

Hariyadi dan Supriyanto, 1991. Pengolahan Kakao Menjadi Bahan Pangan. Pusat Antar Universitas, Pangan dan Gizi, Universitas Gajah Mada, Yoyakarta.

Hayes, A.W., 2001, Principles and methods of Toxicology, 4th ed., Taylor \&Francis, Philadelphia.

ISO 10993-10-1995, Biological Evaluation ofMedical Devices - Part 10; test for Irritation and Sensitization, Geneva, 1995, 2-5.

LLowe, N.J., 1990, Sun Protection Factors: Comparative Techniques andselection of Ultraviolet Sources, in Sunscreen: Development, Evaluation, and Regulatory Aspects, Lowe, N.J. and N. A., Shaath (Eds.,), Marcel Dekker Inc.,New York.

Nursiah Hasyim dan Karunia. 2008. Formulasi Sari Mentimun (Cucumis sativus L.) sebagai Krim Masker dengan Berbagai Konsentrasi Emulgator Nonionik. (http://jurnal.pdii.lipi.go.id//admin/ jurnal/122084245) diakses 03-07- 2011

Primadiati,R. 2001. Kecantikan, Kosmetika. dan Estetika. Gramedia Pustaka Utama,Jakarta.
Ramlah,S. et al, 2007. Pengaruh Proses Fermentasi Terhadap Komponen Utama Organik Biji Kakao. Laporan Hasil Penelitian. Balai Besar Industri Hasil Perkebunan Makassar

Ritter, L. and C.A., Franklin, Dermal Toxicity Testing: Exposure and Absorption, in Handbook of In vivo Toxicity Testing, 1990, D.L. Arnold, H. C. Grice, and D.R.Krewski (Eds.,) Academic press, Inc., Toronto 247-257

Ritter, L. and C.A., Franklin, Dermal Toxicity Testing: Exposure and Absorption, inHandbook of In vivo Toxicity Testing, 1990, D.L. Arnold, H. C. Grice, and D.R.

Krewski (Eds.,) Academic press, Inc., Toronto 247-257

Kanisius, 2001, Budidaya Rumput Laut, Gramedia Pustaka Utama , Jakarta

Soehargo, (2001), Daya Saing Kakao dan Produk Kakao. Training Quality Assurance in Cacao Processing. Program Studi Teknologi Hasil Perkebunan., Fakultas Teknologi Pertanian Universitas Gadjah Mada.

Suprapti, et al, 2011, Pembuatan Makanan Kesehatan Dari Pasta Cokelat Non Fermentasi Kaya Polifenol. Laporan Hasil Penelitian. Balai Besar Industri Hasil Perkebunan Makassar

Soehargo, (2001), Daya Saing Kakao dan Produk Kakao. Training Quality Assurance in

Cacao Processing. Program Studi Teknologi Hasil Perkebunan., Fakultas Teknologi

Pertanian Universitas Gadjah Mada.

Tranggono, R.L.S., 1992. Kiat Apik Menjadi Sehat dan Cantik. Gramedia Pustaka Utama, Jakarta.

Wattimena, J.R., dan J.P. Siregar (Penerjemah dan penyunting), BEBERAPAPOKOK PENGUJIAN MUTU PERBEKALAN FARMASI, PPOM, Dirjen POM, DepKes RI, 1986.

Wanda S.Atmadja, Achmad dkk, 2005, Artikel Pengenalan Jenis-jenis Rumput laut Indonesia, Puslitbang Oseanologi- LIPI. 